\title{
Sarma Deresi Havzasındaki Yağışın Ayrışma ve Su Kalitesine Etkisi, Düzce, Türkiye
}

The Effects of Rainfall on Water Quality and Weathering in the Sarma Stream Basin, Duzce, Turkey

\section{Rüstem PEHLIVAN}

İstanbul Üniversitesi, Mühendislik Fakültesi, Jeoloji Mühendisliği Bölümü, Avcılar ISTANBUL

$\begin{array}{lll}\text { Geliş (received) } & : & \text { 21 Mart (March) } 2016 \\ \text { Düzeltme (revised) } & : & 18 \text { Nisan (April) } 2016 \\ \text { Kabul (accepted) } & : & \text { 19 Nisan (April) } 2016\end{array}$

\section{ÖZ}

Sarma Deresi, Düzce ili Akçakoca İlçesinde bulunur. Su havzası yaklaşı $121.2 \mathrm{~km}^{2}$ 'lik bir alan kaplar. Sarma Deresi, yağışlı dönemde bulanık akar ve Karadeniz’e 85 1/s debi ile dökülür. Akçakoca ilçesindeki içme suyu ihtiyacını karşılamak amacıyla Sarma Deresi havzasında Sarıyayla Barajı'nın yapılmasına karar verilmiştir. Asit yağışı ve etkileri konusundaki araştırmalar Türkiye'de İstanbul özelinde yapılmıştır. Bu nedenle, asit yağışların Sarma Deresi suyunun hidrojeokimyasal özelliklerine etkisini değerlendirmek için Sarma Deresi su havzasından kayaç, toprak, dere suyu, askıda katı madde, dere çamuru ve yağış örnekleri alınmıştır. Araştırma sahasındaki yağışların pH değeri 5.6'nın altındadır. Dere sularında iyon zenginleşmesinde ve jeolojik birimlerin ayrışmasında asidik yağışın etkisi vardır. Dere çamuru örneği ile askıda katı madde örneğine ait Kimyasal Ayrışma İndeks (CIA) değerleri sırasıyla 76 ve 77'dir. Yağışlı dönemde, Sarma Deresi'nin bulanık akmasına, su havzasında mostra veren kil minerallerince zengin kumtaşları ve toprak neden olur. Sarma Deresi'nin yağışlı dönemdeki askıda katı madde miktar1 $70 \mathrm{mg} / \mathrm{l}$ 'dir. Sarma Deresi suyu kalsiyum ve bikarbonatca zengindir. Yağmur suyu, kar suyuna göre $\mathrm{NH}_{4}, \mathrm{NO}_{3}$ ve $\mathrm{SO}_{4}$ iyonlarınca, kar suyu da yağmur suyuna göre $\mathrm{Al}, \mathrm{Ba}, \mathrm{Cu}, \mathrm{Pb}, \mathrm{Mn}, \mathrm{Ni}, \mathrm{Si}, \mathrm{U}$ ve Zn elementlerince zengindir. Yağmur, kar ve dere suyu örneklerindeki Al, Ba, B, Fe, Mn ve Zn gibi bazı ağır metal ve elemenetlerin konsantrasyon miktar1 10 ppb üzeridir. Sarma Deresi suyu, içme suyu gösterge limit değerlerini (örneğin Al, Fe ve Mn elementleri bakımından) aşmaktadır. Bu nedenle, Sarıyayla Baraj suyunda arıtma işlemine gereksinim olabilir.

Anahtar Kelimeler : Asit Yağışı, Ayrışma, Sarma Deresi, Su Kalitesi.

R. Pehlivan

E-Posta:pehlivan@istanbul.edu.tr 
Pehlivan

\section{ABSTRACT}

The Sarma Stream is located in southwest of Akcakoca town in Duzce City, Turkey. Its drainage basin is approximately $121.2 \mathrm{~km}^{2}$. The Sarma stream flows muddy into the Black Sea with an output of $85 \mathrm{l} / \mathrm{s}$ during rainy season. It was decided that the Sariyayla reservoir should be built on the Sarma Stream for the drinking water needs of Akcakoca. Chemical compounds in natural water are altered by interactions with geologic units, by physical and chemical weathering and environmental factors. Generally, research on acid rain and its effect has been done in Istanbul. In this study, effects of acid rainfall on the hydrogeochemistry of the Sarma stream water were investigated. Therefore, samples of rock, soil, rainfall, stream water, suspended and bed sediments were taken in the Sarma Stream basin. The pH of rainfall and snowmelt in the research area are below 5.6. Acid rain affects the dissolution of the geological units and the abundance of principal ions in stream water. The Chemical Index of Alteration (CIA) values of the bed sediment sample and suspended sediment sample are 76 and 77, respectively. Sandstone, which erodes easily and is rich in clay minerals, causes the Sarma Stream to become muddy during the rainy season. The suspended sediment amount of the Sarma Stream in the rainy season is $70 \mathrm{mg} / \mathrm{l}$. The water of the Sarma Stream is rich in calcium and bicarbonate. Rain water is richer in $\mathrm{NH}_{4}$ $\mathrm{NO}_{3}$ and $\mathrm{SO}_{4}$ ions than snowmelt. Snowmelt is richer than rain water in heavy metals such as $\mathrm{Al}, \mathrm{Ba}, \mathrm{Cu}$, $\mathrm{Pb}, \mathrm{Mn}, \mathrm{Ni}, \mathrm{Si}, \mathrm{U}$ and $\mathrm{Zn}$. The concentration of heavy metals and some elements such as $\mathrm{Al}, \mathrm{Ba}, \mathrm{B}, \mathrm{Fe}, \mathrm{Mn}$ and $\mathrm{Zn}$ are $10 \mathrm{ppb}$ and more in rain, snowmelt and stream water. Some ions in the Sarma Stream basin waters exceed the drinking indicator water limit values (e.g. Al, Fe and Mn ions). Hence, water in the Sariyayla Reservoir might need to be treated.

Key Words : Acid Rain, Weathering, Sarma Stream, Water Quality.

\section{GíRIŞ}

Akçakoca, Düzce ilinin deniz kenarındaki tek ilçesidir. $463 \mathrm{~km}^{2}$ lik yüzölçümüne sahip Akçakoca' da 8 mahalle ve 43 köy bulunmaktadır. Akçakoca'nın nüfusu 37.119'dur. Tatil bölgesi olduğu için nüfus, yaz aylarında 100.000 kişiye ulaşır.

Akçakoca ilçesinde çok uzun süredir devam eden içme suyu sorununu çözmek için Devlet $\mathrm{Su}$ İşleri (DSİ) tarafından Sarma Deresi üzerinde bir içme suyu barajının yapılmasına karar verilmiştir (Şekil 1a). Temeli 2013 yılının Ağustos ayında atılan Sarıyayla Barajı'nda 2016 yılı Ağustos ayından itibaren su tutulmaya başlanacaktır. Su havzası $35 \mathrm{~km}^{2}$ olan Sarıyayla Barajı'nda yaklaşık 5 milyon $\mathrm{m}^{3}$ su birikecektir. Sarıyayla Barajı'nın gövdesi beton, yüksekliği ise 63 metre olacaktır.

Bu çalışmada, asidik yağışların ve su - kayaç etkileşiminin Sarıyayla Barajı'nda birikecek ham suyun hidrojeokimyasal özelliklerine etkisi araştırılmış, Sarıyayla Barajı ham suyunun içilebilirliği, su kalitesi ve insan sağlığına etkisi belirlenmeye çalışılmıştır. 


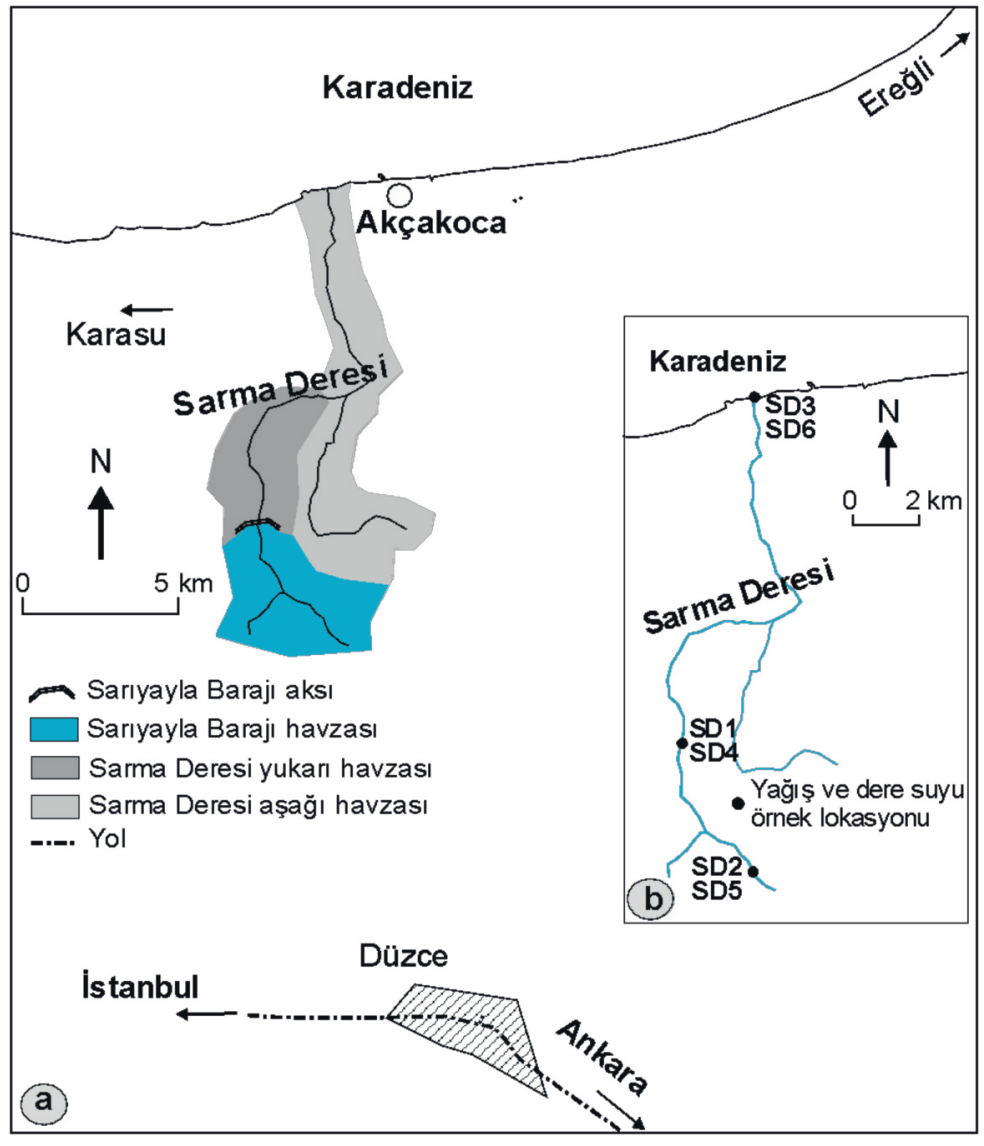

Şekil 1. İnceleme alanının (a) su havzası ve (b) su örneği lokasyon haritaları.

Figure 1. Location maps of (a) the drainage basin and (b) the water sample of the study area.

\section{ÖNCEKİ ARAŞTIRMALAR}

Bilindiği gibi, doğal suların kimyasal bileşimleri, jeolojik birimlerle olan etkileşim, çevre kayaçlarda gelişen fiziksel ve kimyasal ayrışmalar ve çevresel etkenler ile değişir. $\mathrm{Bu}$ sularda insan sağlı̆ olabilecek (WHO, 2011; EPA, 2009) baz1 ağır metallerin ve iyonların bulunması hâlinde su kirliliğinden söz edilebilir. Su kirliliğine az oranda jeolojik birimler, yaygın olarak çevresel faktörler (evsel ve sanayi sıvı atıkları, tarımsal verimi arttırmak için kullanılan gübreler ile asit yağışları) neden olur.
Doğal ve çevresel kaynaklı su kirliliği, sukayaç etkileşimi, su kimyası, su kalitesi, dere çamuru, askıda katı madde jeokimyası ve asit yağışlarının çevresel etkisi konusunda çok sayıda çalışma yapılmıştır. Bu çalışmalardan bazıları, özetle, asit yağışlarının sucul ekosistemlere etkisi Gorham (1976) tarafindan, Avrupa'daki asit yağışları HettelinghHettelingh ve Hordijk (1986) tarafından, dere çamurlarında metal birikimi ve su kalitesi Kumar vd. (1998) tarafindan, Hindistan'da, Avrupa'da ve Amerika Birleşik Devletleri'ndeki (ABD) asit yağışları Menz ve Seip (2004) tarafından, askıda katı madde ve 
dere çamurlarının jeokimyası Piper vd. (2006) tarafindan, Mississippi Nehri'nde, asit yağışının granitlerdeki kimyasal ayrışmaya etkisi Lee vd. (2009) tarafindan, Kore'de, atmosferik nitrojen ve sülfür oluşumu Im vd. (2013) tarafindan, Güneydoğu Avrupa, Akdeniz ve Karadeniz'de, Jianghan havzasının hidrojeokimyasal özellikleri Zhou vd. (2013) tarafından, Çin'de, asit yağışlarının kimyasal bileşimi ve $\mathrm{Zn}, \mathrm{Al}, \mathrm{Pb}$, $\mathrm{Ba}$, As ve $\mathrm{Cr}$ elementlerince zengin olan asit yağışlarının suya, bitkiye ve insan sağlığına etkisi Sun vd. (2015) tarafindan çalışılmıştır.

Türkiye'de ise benzer konulardaki araştırmalar sınırlı sayıda olup, asit yağışı ve etkileri konusundaki araştırmalar genellikle İstanbul özelinde yapılmıştır. Asit yağışlarının çevreye etkisi Toros vd. (1997) ile Toros (2000) tarafından, asit yağışlarının içme suyu kaynaklarına etkisi Alp vd. (2004) tarafindan, İstanbul'da görülen asidik yağışların $\mathrm{Cd}, \mathrm{Cu}, \mathrm{V}$, $\mathrm{Zn}, \mathrm{Ni}, \mathrm{Pb}$ ve $\mathrm{Cr}$ gibi ağır metallerce zenginliğinin belirlenmesi Başak ve Alagha (2010) tarafindan çalışılmıştır. Zirai üretimin çevreye etkisi konusunda Keskin (2010) tarafindan yapilan araştırma ile de Eskipazar Çayı ham suyunun bazı ağır metallerle ve nitrat iyonunca kirlendiği belirlenmiştir.

\section{MATERYAL VE METOT}

Sarma Deresi havzasından yağmur, kar ve dere suyu örnekleri yağışlı (Aralık 2012 ve Şubat 2013) ve kurak (Haziran 2013) dönemlerde, kayaç, toprak ve dere sedimenti örnekleri yaz dönemi arazi çalışması esnasında, dere çamuru ve askıda katı madde örnekleri ise yağışlı dönemde alınmıştır.

Yağış ve dere suyu örneklerinin elektriksel iletkenlik (Ec) ve pH değerleri arazide ölçülmüştür. Su örneklerinin ana iyon analizleri ( $\mathrm{Na}, \mathrm{K}, \mathrm{Ca}, \mathrm{Mg}, \mathrm{SO}_{4}, \mathrm{HCO}_{3}, \mathrm{Cl}, \mathrm{NH}_{4}, \mathrm{NO}_{3}$, $\mathrm{PO}_{4}$ ) İstanbul Halk Sağlığı Laboratuvarı'nda yaptırılmıştır. Yağış ve dere suyu örneklerindeki $\mathrm{NO}_{3}, \mathrm{SO}_{4}, \mathrm{Cl}$ ve $\mathrm{PO}_{4}$ iyonları kromotografi yöntemiyle, $\mathrm{NH}_{4}$ iyonu spektrofotometri yöntemiyle, $\mathrm{HCO}_{3}$ iyonu titrimetrik yöntemle, $\mathrm{Na}, \mathrm{K}, \mathrm{Ca}$ ve $\mathrm{Mg}$ iyonlarının analizleri ise "İndüktif Olarak Eşleştirilmiş Plazma-Kütle Spektrometresi" (Inductively Coupled PlasmaMass Spectrometer - ICP-MS) ile yapılmıştır. Iyon yük dengesi hesabına göre analiz hata yüzdesi \pm 7.9 olarak bulunmuştur. Ağır metal analizi için alınan yağış ve dere suyu örnekleri + $4 \mathrm{C}^{\circ}$ ' deki ortamda, $\mathrm{HNO}_{3}$ asiti ile koruma altında tutulmuştur. Su örneklerininin bazı ağır metal ve bazı element analizleri (Al, Fe, As, Ag, Hg, Co, $\mathrm{Cd}, \mathrm{Cr}, \mathrm{Pb}, \mathrm{Ni}, \mathrm{Ti}, \mathrm{Ba}, \mathrm{Mn}, \mathrm{Zn}, \mathrm{Cu}, \mathrm{Se}, \mathrm{Sb}, \mathrm{B}$ ve U) ise ALS Global (Kanada) laboratuvarında ICP-MS yöntemi ile yaptırılmıştır. Dere suyu örnekleri için ortalama ve standart sapma değerleri hesaplanmıştır. Kayaç örneklerinin mineralojik ve petrografik incelemeleri polarizan mikroskobu ile; dere sedimenti, toprak, çamur ve askıda katı madde örneklerinin mineralojik bileşimleri ise X-1şını difraksiyonu (XRD) ile belirlenmiştir. Örneklerin XRD çekimleri İstanbul Üniversitesi İleri Analizler Laboratuvarı'nda yaptırılmıştır. Kayaç, toprak, askıda katı madde ve dere çamuru örneklerindeki ana element $\left(\mathrm{SiO}_{2}, \mathrm{Al}_{2} \mathrm{O}_{3}, \mathrm{Fe}_{2} \mathrm{O}_{3}, \mathrm{MgO}, \mathrm{MnO}\right.$, $\left.\mathrm{CaO}, \mathrm{TiO}_{2}, \mathrm{Na}_{2} \mathrm{O}, \mathrm{K}_{2} \mathrm{O}, \mathrm{P}_{2} \mathrm{O}_{5}, \mathrm{AK}\right)$ analizleri XRF yöntemiyle, iz element (Al, Fe, As, Ag, $\mathrm{Hg}$, Co, $\mathrm{Cd}, \mathrm{Cr}, \mathrm{Pb}, \mathrm{Ni}, \mathrm{Ti}, \mathrm{Ba}, \mathrm{Mn}, \mathrm{Zn}, \mathrm{Cu}, \mathrm{Se}, \mathrm{Sb}, \mathrm{B}$ ve $\mathrm{U})$ analizleri de ICP-MS yöntemiyle ALS Global (Kanada) laboratuvarında yaptırılmıştır. Kayaç gruplandırmasındaki sayı da 3'ten az olduğu için standart hata değerlendirmesi yapılamamıştır. 


\section{İKLIMM VE YAĞIŞ}

Akçakoca, deniz kıyısında yer aldığı için iklimi nemlidir. Akçakoca'da, sonbahar ve kış aylarında çoğunlukla kar ve karla karışık yağmur yağar. Yıllık ortalama sıcaklık 14.4 $\mathrm{C}^{\circ}$ 'dir. Bölgenin en soğuk ayı Ocak $\left(6.0 \mathrm{C}^{\circ}\right)$, en sıcak ayı ise Ağustos'tur $\left(24.5 \mathrm{C}^{\circ}\right)$. Akçakoca Meteoroloji İstasyonu'nun 2004-2014 y1lar1 arasındaki 11 yllık yağış verisine göre (MGM, 2014), Akçakoca'ya yıllık 894.9 mm'lik yağış düşmüştür. 1970-2013 yılları arasındaki 43 yıllık dönemde Türkiye'de gerçekleşen yağış miktarı ise $644.8 \mathrm{~mm}$ 'dir (MGM, 2013). Bu veriler, araştırma sahası ve yakın çevresinin Türkiye ortalamasına göre çok daha fazla yağış aldığını göstermektedir.

\section{ASITT YAĞISSI}

Kömür ve petrol kökenli fosil yakıtlar, evlerde 1sınma, sanayide elektrik enerjisi elde etme işleminde kullanılır. Kömür ve fosil yakıtların yakılması ile açığa çıkan kükürt ve azot oksitler atmosferde birikir. Atmosferde biriken bu gazlar, kimyasal dönüşümden geçtikten sonra bulutlardaki su damlacikları tarafindan emilir. Böylelikle, sülfürik asit ve nitrik asit damlacıkları oluşur. Bu damlackklar suyun hidrolojik çevrimi sırasında yeryüzüne yağmur veya kar olarak düşer. Asit yağış olarak kabul edilen bu tür yağışların pH'1 5.6'dan küçüktür (Carlson ve Rodhe, 1982; İlhan vd., 2006).
Birçok Avrupa ülkesinde (Örneğin Avusturya, Çek Cumhuriyeti, Finlandiya, Fransa, Almanya, Litvanya, Hollanda, Norveç, Polonya, Portekiz, Rusya, İsveç, İsviçre ve İngiltere) son 32 yıllık dönemde gerçekleşen yağışlar asidik karakterlidir (Lajtha ve Jones, 2013).

Tuncel vd. (1991) tarafindan yapilan "Karadeniz Atmosferinde Eser Element Taşınımı" başlıklıaraştırmada, günümüzden tam 25 y1l önce, Batı Karadeniz Bölgesi'nde görülecek yağışların asidik karakterli olabileceğine yönelik bilimsel görüş dikkat çekicidir.

Asit yağışlarının kaynakları ve etkileri konusunda Toros (2000) tarafindan İstanbul'da gerçekleştirilen araştırmada da ilginç sonuçlar elde edilmiştir. Araştırmaya göre, İstanbul'da gerçekleşen asidik yă̆ışların \% 31'i batıgüneybatı (Yunanistan yönünden), \% 24'ü kuzeykuzeybatı (Avrupa tarafindan), \% 19'u kuzeykuzeydoğu (Sibirya'dan), \% 16'sı bat1-kuzeybatı (Balkanlar'dan) ve \% 9'u ise güney-güneybat1 yönünden (Ege Denizi'nden) gelmektedir.

Sarma Deresi havzasında gerçekleşen yağışların ilk 40 dakikalık süreçteki karakteri asidiktir. 40 dakikadan sonrasındaki süreçte, yağışıı $\mathrm{pH}$ değeri yükselmektedir. Kar yağışında ise bu türden bir özellik gözlenmemiştir. Yağmur ve kar yağışlarının elektriksel iletkenlik (Ec) değerleri zamana bağlı olarak azalmaktadır (Çizelge 1). 
Pehlivan

Çizelge 1. Sarma Deresi yağış örneklerinin zamana bağlı pH ve Ec değişimleri.

Table 1. Temporal variation of $\mathrm{pH}$ and EC values of the rainfall samples.

\begin{tabular}{lccc}
\hline & $\begin{array}{c}\text { Yağmur suyu } \\
(\text { Ekim 2012) }\end{array}$ & $\begin{array}{c}\text { Kar suyu } \\
(\text { Şubat 2013) }\end{array}$ & $\begin{array}{c}\text { Yağmur suyu } \\
\text { (Haziran 2013) }\end{array}$ \\
\hline 1. Kap (0- 20 dakika), pH & $<5.6$ & $<5.6$ & $<5.6$ \\
2. Kap (20-40 dakika), pH & $<5.6$ & $<5.6$ & $<5.6$ \\
3. Kap (40-60 dakika), pH & $>5.6$ & $<5.6$ & $>5.6$ \\
\hline $\mathrm{Ec}_{1}(\mu \mathrm{S} / \mathrm{cm})$ & 45,05 & 56,81 & 95,30 \\
$\mathrm{Ec}_{2}(\mu \mathrm{S} / \mathrm{cm})$ & 42,55 & 56,37 & 85,51 \\
$\mathrm{Ec}_{3}(\mu \mathrm{S} / \mathrm{cm})$ & 35,40 & 51,04 & 58,13 \\
\hline
\end{tabular}

Asit yağışları, toprağın kimyasal yapısını bozar, biyolojik koşullarını etkiler ve üzerinde yetişen bitkilere zarar verir. Topraktaki asit birikimi, besinelementlerinin(Örneğin, $\mathrm{Ca}, \mathrm{K}, \mathrm{Mg}$ ve Na'nın) bitkiler tarafından kullanılamamasına neden olur. Asit yağışları topraktaki Fe, $\mathrm{Al}$ ve $\mathrm{Mn}$ gibi toksik elementleri açığa çıkararak yüzey ve yeraltı suyuna karışmasına neden olur (Carlson ve Haines, 1989).

\section{JEOLOJi}

Araştırma sahasında, temelde amfibolit ve gnays gibi kayaçlardan oluşan Prekambriyen yaşlı Yedigöller Formasyonu yer alır (Şekil 2) ve bunların üzerine uyumsuz olarak şeyl, çamurtaşı ve kumtaşı içeren Alt Ordovisyen yaşlı Kocatöngel Formasyonu ile başlayan İstanbul Palezoyik istifi gelir. İstifin diğer birimi kireçtaşı ve dolomitik kireçtaşından oluşan Orta Devoniyen-Alt Karbonifer yaşlı Yılanlı
Formasyonu'dur. İstanbul Paleozoyik istifinin üzerinde açısal uyumsuzlukla karasal çamurtaşı, kumtaşı ve konglomera ardalanmalı PermiyenTriyas yaştaki Çakraz Formasyonu yer alır. Geçişli olarak Üst kampaniyen-Alt Eosen yaştaki kireçtaşlı fliş karakterindeki Akveren Formasyonu, alttaki birimler üzerine açısal uyumsuzlukla gelir. Bölgenin en genç birimi ise Kuvaterner yaşlı alüvyonlardır (Pehlivan vd., 2002).

Kuzey Anadolu Fayı'nın etkisiyle Sarma Deresi havzasında pek çok fay oluşmuştur. Bu faylardan en önemlisi Sarıyayla Barajı rezervuar alanında yer alan $3 \mathrm{~km}$ uzunluğundaki eğim atımlı faydır. Fay, Sarma Deresi memba kesiminde ve dere yatağında bulunur. Fayın doğrultusu KD - GB yönlüdür. Sarma Deresi havzasında gelişen diğer faylar ise doğrultu atımlıdırlar. Sarıyayla Köyü'nün kuzeyindeki alanda bulunan doğrultulu atımlı faylar sağ yönlüdür. 


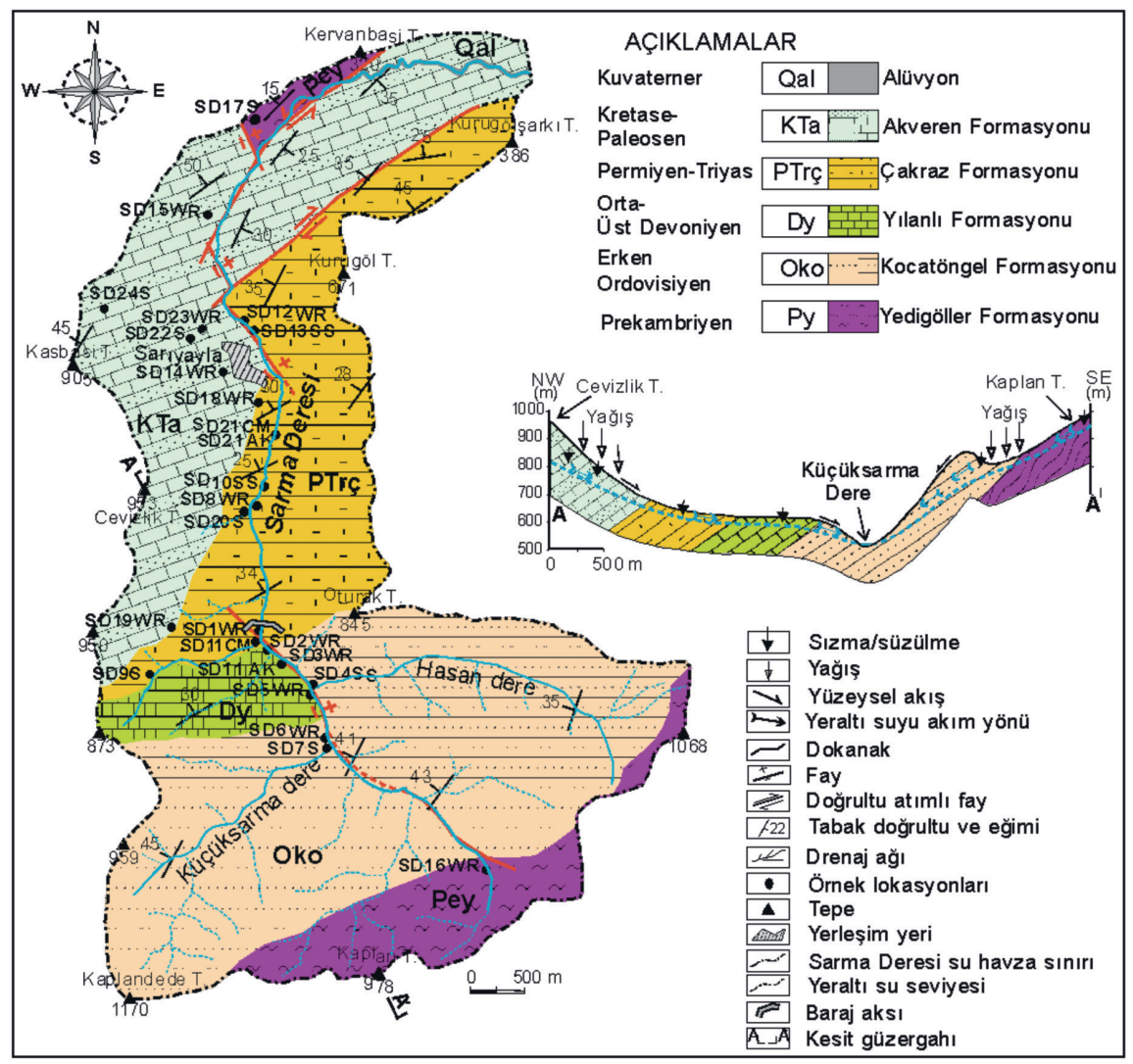

Şekil 2. Sarma Deresi havzasının jeoloji haritası.

Figure 2. Geological map of the Sarma Stream basin.

\section{JEOKIMYY}

Sarma Deresi sedimentleri kuvars, plajiyoklas, k-feldspat, amfibol, klorit ve manyetit gibi mineraller içerir. Askıda katı maddeler, kayaçların fiziksel ayrışması ve zemin erozyonundan dere suyuna geçmektedir. Dere sularında asılı halde bulunan askida katı maddeler, su akımı süresince devamlı olarak askıda kalamayabilirler. Yerçekimi etkisyle sudaki katı maddeler dere tabanında birikerek dere çamurunu oluşturur. Sarma Deresi havzasına ait dere çamuru (SD11CM) ve askıda katı madde (SD11AK) örneklerinde kuvars, plajiyoklas ve kil mineralleri bulunur. Dere çamuru örneklerindeki kil boyutundaki mineraller için kil zenginleştirme çalışması yapılmıştır. Kil fraksiyonlarından hazırlanan plaketlerin X-1şını difraksiyonu çekimine göre, SD11CM nolu dere çamuru örneğinde \% 50 illit, \% 30 klorit ve \% 20 montmorillonit, SD21CM nolu dere çamuru örneğinde ise \% 70 kaolinit ve \% 30 illit minerali saptanmıştır. SD11AK nolu askıda katı madde örneği ise \% 60 kaolinit, \% 20 illit ve \% 20 montmorillonit minerallerinden oluşmaktadır.

Sarma Deresi havzasına ait kayaç, toprak, askıda katı madde ve dere çamuru örneklerinde yapılan ana ve iz element analiz sonuçları Çizelge 2'de ve 3'te verilmektedir. 
Pehlivan

Çizelge 2. Kayaç (WR), toprak (S), askıda katı madde (AK) ve çamur (CM) örneklerinin ana element analiz sonuçları (\%). Table 2. $\quad$ Major oxides compositions (\%) of some rock (WR), soil (S), bed (CM) and suspended sediment (AK) samples.

\begin{tabular}{lccccccccccc}
\hline & $\mathbf{S i O}_{2}$ & $\mathrm{Al}_{2} \mathbf{O}_{3}$ & $\mathbf{F e}_{2} \mathbf{O}_{3}$ & $\mathbf{C a O}$ & $\mathbf{M g O}$ & $\mathbf{N a}_{2} \mathbf{O}$ & $\mathbf{K}_{2} \mathbf{O}$ & $\mathbf{T i O}_{2}$ & $\mathbf{M n O}$ & $\mathbf{P}_{2} \mathbf{O}_{5}$ & $\mathbf{L O I}$ \\
\hline SD2WR & 0.56 & 0.15 & 0.05 & 55.04 & 0.42 & $<0.01$ & 0.02 & $<0.01$ & 0.03 & 0.01 & 43.6 \\
SD6WR & 44.65 & 10.23 & 4.66 & 18.23 & 1.88 & 0.73 & 2.43 & 0.54 & 0.14 & 0.075 & 15.55 \\
SD7S & 58.88 & 15.18 & 5.96 & 4.38 & 2.14 & 0.82 & 3.69 & 0.87 & 0.04 & 0.141 & 7.1 \\
SD8WR & 95.48 & 1.40 & 1.30 & 0.07 & 0.10 & 0.03 & 0.27 & 0.09 & $<0.01$ & 0.021 & 0.56 \\
SD9S & 76.26 & 9.87 & 4.26 & 0.21 & 0.70 & 0.62 & 1.38 & 0.68 & 0.07 & 0.074 & 5.39 \\
SD12WR & 74.66 & 3.89 & 2.37 & 8.33 & 0.56 & 0.55 & 1.00 & 0.26 & 0.01 & 0.048 & 7.34 \\
SD14WR & 13.60 & 2.77 & 1.86 & 43.99 & 0.38 & 0.13 & 0.28 & 0.12 & 0.10 & 0.038 & 36.3 \\
SD16WR & 47.46 & 15.65 & 9.57 & 9.43 & 8.26 & 2.75 & 1.18 & 1.04 & 0.16 & 0.072 & 4.07 \\
SD11CM & 61.67 & 13.77 & 5.69 & 1.19 & 1.32 & 1.05 & 2.03 & 0.82 & 0.13 & 0.151 & 11.6 \\
SD11AK & 59.69 & 15.06 & 6.1 & 1.09 & 1.45 & 0.94 & 2.29 & 0.87 & 0.12 & 0.177 & 11.5 \\
\hline UCC & 65.70 & 15.10 & 4.93 & 4.2 & 2.19 & 3.9 & 3.40 & 0.5 & 0.08 & 0.06 & - \\
\hline
\end{tabular}

${ }^{a}$ Üst Kitasal Kabuk (Upper Continental Crust, UCC) (Taylor ve McLennan,1995)

Çizelge 3. Kayaç (WR), toprak (S), çamur (CM) ve askıda katı madde (AK) örneklerinin iz element analiz sonuçları (ppm). Table 3. Trace element analysis results (ppm) in rock (WR), soil (S), bed (CM) and suspended sediment (AK) samples.

\begin{tabular}{|c|c|c|c|c|c|c|c|c|c|c|c|c|c|c|c|}
\hline & Ag & As & $\mathbf{B a}$ & Cd & Co & $\mathrm{Cr}$ & $\mathrm{Cu}$ & Hg & $\mathbf{N i}$ & $\mathbf{P b}$ & $\mathbf{S b}$ & Se & $\mathbf{U}$ & Zn & $\mathbf{Z r}$ \\
\hline SD2WR & 0.03 & $<5$ & 10 & 0.05 & 0.6 & 2 & 1.7 & $<0.1$ & 3.9 & 8.8 & 0.27 & 1 & 1.6 & 10 & 1.9 \\
\hline SD6WR & 0.27 & 9 & 270 & 0.05 & 15.1 & 52 & 20 & 0.02 & 32.6 & 26.8 & 0.59 & 1 & 1.7 & 53 & 82.5 \\
\hline SD7S & 0.17 & 24.6 & 360 & 0.03 & 26.3 & 98 & 52.3 & 0.03 & 64.3 & 44.7 & 1.14 & 2 & 2.8 & 59 & 139 \\
\hline SD8WR & 0.06 & 10.2 & 40 & 0.03 & 1.3 & 17 & 5.7 & $<0.01$ & 5 & 4.8 & 0.35 & 1 & 0.6 & 37 & 21.7 \\
\hline SD9S & 0.05 & 8.2 & 230 & 0.07 & 10.8 & 59 & 15.5 & 0.04 & 27.6 & 13.1 & 0.62 & 2 & 2.5 & 61 & 92 \\
\hline SD12WR & 0.05 & 3.7 & 170 & 0.06 & 4.2 & 29 & 5.5 & $<0.01$ & 11 & 6.7 & 0.27 & 1 & 1 & 34 & 29 \\
\hline SD14WR & 0.04 & $<5$ & 780 & 0.23 & 5.7 & 15 & 17.5 & 0.02 & 13.8 & 6.5 & 0.28 & 1 & 0.4 & 30 & 18 \\
\hline SD16WR & 0.05 & 2.4 & 290 & 0.08 & 37.6 & 247 & 119 & 0.03 & 112 & 1.3 & $<0.05$ & 2 & 0.1 & 70 & 9 \\
\hline SD11CM & 0.09 & 9.5 & 370 & 0.25 & 17.9 & 78 & 36.1 & 0.06 & 44.4 & 19.3 & 0.83 & 2 & 2.2 & 104 & 106 \\
\hline SD11AK & 0.09 & 9.9 & 410 & 0.24 & 18.5 & 80 & 38.6 & 0.06 & 48.6 & 20.1 & 0.89 & 2 & 2.2 & 122 & 111 \\
\hline $\mathbf{U C C}$ & 0.05 & 1.5 & 550 & 0.1 & 10 & 35 & 25 & 0.04 & 20 & 20 & 0.2 & 50 & 2.8 & 71 & 190 \\
\hline
\end{tabular}

\section{Kayaç, Toprak, Askıda Katı Madde ve Dere Çamur Örneklerinin Elementel Oranı}

Askıda katı madde ve dere çamuru örneklerinin kimyasal bileşimi, ayrışmaya uğrayanjeolojik birimlerden çözülen elementlerin mobilitesine bağlı olarak değişir (Stallard, 1988). Sarma Deresi havzasında gelişen ayrışmanın askıda madde ve dere çamuru örneklerindeki ana ve iz element miktarına yansımasını değerlendirmek için mobilitesi az olan $\mathrm{Al}_{2} \mathrm{O}_{3}$ ve Üst Kitasal kabuk (Upper Continental Crust, UCC) değerleri (Çizelge 2 ve 3) baz alınarak:

Elementel oran $(\mathrm{x})=\mathrm{X} / \mathrm{Al}_{2} \mathrm{O}_{3}($ Sarma Deresi Sedimentleri) $\mathrm{X} / \mathrm{Al}_{2} \mathrm{O}_{3}$ (Üst Kitasal Kabuk)

formülü ile hesaplanmıştır. Formüldeki $X$ değişkendir. Formüldeki X yerine, dere sedimenti örneğine ait ana element analiz sonuçların $\left(\mathrm{Al}_{2} \mathrm{O}_{3}\right.$ hariç) değerleri ayrı ayrı yazılarak elementel oranlar1 belirlenir. 
Sarma Deresi havzasında mostra veren arduvaz (SD6WR) ile arduvazın fiziksel ayrışması ile oluşmuş toprak örneği (SD7S), kumtaş1 (SD12WR) ile fiziksel ayrışma sonucu oluşmuş toprak örneği (SD9S), volkanik kumtaş1 (SD14WR) ve amfibolit kuvars şist (SD16WR) örneklerindeki $\mathrm{Al}_{2} \mathrm{O}_{3}$ miktarı baz alınarak UCC'ye ait jeokimyasal verilere göre belirlenmiş element oranlarının değişimleri Çizelge $4^{\text {'te }}$

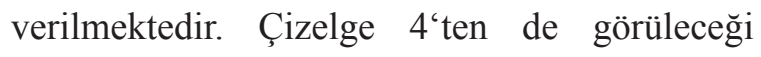
üzere, volkanik kumtaşı (SD14WR), kumtaş1 (SD12WR) ve toprak (SD9S) örneğindeki çok sayıda element UCC'ye göre daha zengindir.

Dere çamuru örneği (SD11CM), askıda katı madde (SD11AK) örneğine göre $\mathrm{Al}_{2} \mathrm{O}_{3}(\%$ 13.77) ve $\mathrm{Fe}_{2} \mathrm{O}_{3}\left(\begin{array}{ll}\% & 6.1\end{array}\right)$ açısından daha zengindir. Askıda katı madde örneği ise $\mathrm{UCC}^{\prime}$ ye göre $\mathrm{TiO}_{2}$ ve $\mathrm{Zn}$ açısından zenginleşmiştir.

Çizelge 4. Bazı kayaç, toprak ve çamur örneklerinin UCC'a göre zenginleşme oranları.

Table 4. Enrichment rates of some rock, soil and bed sediment samples according to UCC.

\begin{tabular}{llccccccccc}
\hline & $\mathbf{S i O}_{2}$ & $\mathbf{F e}_{2} \mathbf{O}_{3}$ & $\mathbf{C a O}$ & $\mathbf{M g O}$ & $\mathbf{N a}_{2} \mathbf{O}$ & $\mathbf{K}_{2} \mathbf{O}$ & $\mathbf{T i O}_{2}$ & $\mathbf{M n O}$ & $\mathbf{P}_{2} \mathbf{O}_{5}$ \\
\hline SD6WR & Arduvaz & 1.47 & 0.46 & 1.48 & 1.5 & 1.4 & 1.43 & 1.25 & 1.11 & 1.75 \\
SD7S & Toprak (arduvaz) & 0.99 & 1 & 0.96 & 1 & 1 & 1 & 1 & 1 & 1 \\
SD9S & Toprak (kumtaş1) & 1.52 & 1.53 & 44 & 1.75 & 1.5 & 4.11 & 1.12 & 1.75 & 1.75 \\
SD12WR & Kumtaş1 & 3.88 & 4 & 3.9 & 3.5 & 3.5 & 4.16 & 3.52 & 3.33 & 4 \\
SD14WR & Volkanik Kumtaş1 & 5.44 & 5.58 & 5.45 & 4.33 & 0.44 & 5 & 5.71 & 6.66 & 4.3 \\
SD16WR & Metebazit & 0.96 & 0.96 & 0.96 & 0.96 & 0.94 & 0.88 & 1.14 & 1 & 1.25 \\
SD21CM & Çamur & 1.1 & 1.1 & 1.28 & 1.12 & 1.14 & 1.07 & 1.2 & 1.25 & 1 \\
SD21AK & Askıda katı & 1 & 1 & 1 & 1 & 1 & 1 & 1.2 & 0.88 & 1 \\
\hline
\end{tabular}

Çizelge 4. (devam1).

Table 4. (Cont'd).

\begin{tabular}{lccccccccccccccc}
\hline & Ag & As & Ba & $\mathbf{C d}$ & $\mathbf{C o}$ & $\mathbf{C r}$ & $\mathbf{C u}$ & $\mathbf{H g}$ & $\mathbf{N i}$ & $\mathbf{P b}$ & $\mathbf{S b}$ & $\mathbf{S e}$ & $\mathbf{U}$ & $\mathbf{Z n}$ & $\mathbf{Z r}$ \\
\hline SD6WR & 1.1 & 1.4 & 1.3 & 1.6 & 1.5 & 4.98 & 1.47 & 2 & 1.47 & 1.48 & 1.25 & 1.28 & 1.45 & 1.48 & 1.47 \\
SD7S & 0.9 & 1 & 0.99 & 1 & 1 & 0.99 & 0.99 & 1 & 0.99 & 0.99 & 0.87 & 1 & 1 & 0.99 & 0.97 \\
SD9S & 1.6 & 1.5 & 1.5 & 1.75 & 1.46 & 1.53 & 1.53 & 2 & 1.53 & 1.53 & 1.5 & 1.53 & 1.56 & 1.52 & 1.53 \\
SD12WR & 3.3 & 4 & 3.8 & 3.75 & 3.82 & 3.88 & 3.91 & 3.3 & 3.91 & 3.9 & 4.1 & 3.57 & 3.57 & 3.88 & 3.88 \\
SD14WR & 3 & 0.2 & 5.4 & 5.3 & 0.82 & 5.46 & 5.43 & 7 & 5.5 & 5.2 & 0.55 & 5.14 & 7 & 5.46 & 5.46 \\
SD16WR & 1 & 1 & 0.96 & 1 & 1 & 0.96 & 0.96 & 0.5 & 0.96 & 0.93 & 1 & 0.92 & 0.1 & 0.96 & 0.96 \\
SD21CM & 1 & 1.1 & 1.09 & 1.1 & 1.08 & 1.09 & 1.09 & 1 & 1.06 & 1.09 & 1.1 & 1.07 & 1.07 & 1.09 & 1.09 \\
SD21AK & 1 & 1 & 1 & 1 & 1 & 1 & 1 & 0.75 & 1 & 1 & 1 & 1 & 1 & 1.1 & 1 \\
\hline
\end{tabular}


Pehlivan

\section{Kimyasal Mobilite ve Kimyasal Ayrışma İndeksi}

Kayaçların ayrışması sonrasında dere yataklarında biriken dere çamuru ve sularda serbest halde bulunan katı madde örneklerindeki major ve iz elementlerin zenginleşmesi, elementlerin kimyasal mobilitelerine gore gerçekleşmektedir. Kimyasal mobiliteyi, birincil ve ikincil minerallerin taşınması, minerallerdeki iyon değişimi, redoks potansiyeli ve yeniden çökelme gibi değişik aşamalar etkiler (Chesworth vd., 1981). Ayrışmalarda immobil olan Ti elementi ve UCC değerleri baz alınarak kimyasal mobilite, Nesbitt (1979) tarafindan önerildiği şekilde, $\%$ değişism $=\left[\left(\mathrm{X} / \mathrm{TiO}_{2}\right)_{\text {sample }} /\left(\mathrm{X} / \mathrm{TiO}_{2}\right)_{\mathrm{UCC}}\right.$ -1] formülü ile hesaplanabilir.
Jeolojik birimlerin kimyasal ayrışmasında, ayrışmanın değeri kimyasal ayrışma indeks (Chemical Index of Alteration, CIA) formülü ile ifade edilebilir (Nesbitt ve Young, 1982) ve CIA $=\left[\mathrm{Al}_{2} \mathrm{O}_{3} /\left(\mathrm{Al}_{2} \mathrm{O}_{3}+\mathrm{CaO}^{*}+\mathrm{Na}_{2} \mathrm{O}+\mathrm{K}_{2} \mathrm{O}\right)\right] \times 100$ şeklinde hesaplanır. Çamur (SD11CM) ve askıda katı madde (SD11AK) örneklerine ait kimyasal ayrışma indeks değerlerinin sırasıyla 76 ve 77 olarak belirlenmiş olması, Sarma havzası jeolojik birimlerinde orta derecede kimyasal ayrışmanın (Price ve Vebel, 2003) olduğuna işarettir.

\section{HIDDROJEOKIMYYA}

Sarma Deresi kış aylarında 140 1/s, yaz aylarında ise 60 1/s debi ile Karadeniz'e dökülür. Dereyi besleyen yeraltı sularının akım yönü

Çizelge 5. Sarma Deresi havzası çamur ve askıda katı madde örneklerinin kimyasal mobilite değerleri.

Table 5. Chemical mobility values of the bed and suspended sediment samples in the Sarma Stream basin.

\begin{tabular}{lccccccccc}
\hline & $\mathrm{SiO}_{2}$ & $\mathrm{Al}_{2} \mathrm{O}_{3}$ & $\mathrm{Fe}_{2} \mathbf{O}_{3}$ & $\mathbf{C a O}$ & $\mathbf{M g O}$ & $\mathbf{N a}_{2} \mathbf{O}$ & $\mathbf{K}_{2} \mathbf{O}$ & $\mathbf{M n O}$ & $\mathbf{P}_{2} \mathbf{O}_{5}$ \\
\hline $\begin{array}{l}\text { SD11CM } \\
\text { (Çamur örneği) }\end{array}$ & 61 & 60 & 61 & 60 & 60 & 60 & 60 & 57 & 60 \\
$\begin{array}{l}\text { SD11AK } \\
\text { (Askıda katı ) }\end{array}$ & 57 & 57 & 57 & 57 & 57 & 57 & 56 & 57 & 57 \\
\hline
\end{tabular}

Cizelge 5. (devam1).

Table 5. (Cont'd).

\begin{tabular}{lccccccccccccccc}
\hline & Ag & As & Ba & Cd & Co & Cr & Cu & Hg & Ni & Pb & Sb & Se & U & Zn & Zr \\
\hline $\begin{array}{l}\text { SD11CM } \\
\text { (Çamur örneği) }\end{array}$ & 60 & 61 & 60 & 57 & 57 & 57 & 57 & 57 & 57 & 57 & 60 & 60 & 60 & 60 & 60 \\
$\begin{array}{l}\text { SD11AK } \\
\text { (Askıda katı) }\end{array}$ & 57 & 57 & 57 & 57 & 57 & 57 & 57 & 57 & 57 & 57 & 57 & 57 & 57 & 57 & 57 \\
\hline
\end{tabular}

Hesaplama sonucunda, dere çamuru (SD11CM) ve askıda katı madde (SD11AK) örneklerindeki elementlerin kimyasal mobilite değerlerinin \% 57 ile \% 61 arasında değiştiği belirlenmiştir (Çizelge 5).
Karadeniz'e doğrudur. Araştırma sahasındaki akiferler yağmur ve kar yağışlarından beslenir. Sarma Deresi'nin yaz aylarında kurumamasının en önemli nedeni kışın yağan karların yaz aylarına doğru erimesidir. Sarma Deresi havzasında yüzlek veren jeolojik birimler, 
hidrojeolojik olarak geçirimli ve yarı geçirimli özelliğe sahiptir.

Sarma deresi havzasından Aralik 2012, Şubat 2013 ve Haziran 2013'te alınan yağmur, kar ve dere suyu örneklerinin (Şekil 1b) $\mathrm{pH}$ ve Ec değerleri arazide ölçülmüştür. $\mathrm{Na}, \mathrm{K}$, $\mathrm{Ca}, \mathrm{Mg}, \mathrm{SO}_{4}, \mathrm{HCO}_{3}, \mathrm{Cl}, \mathrm{NH}_{4}, \mathrm{NO}_{3}$ ve $\mathrm{PO}_{4}$ gibi ana iyonların analizleri ise laboratuvarda yaptırılmıştır (Çizelge 6).

SD1 nolu yağmur suyunun kat1 inorganik madde (TDS) içeriği $27.0 \mathrm{mg} / 1$, SD4 nolu kar suyunun TDS içeriği $45.8 \mathrm{mg} / \mathrm{l}$, Sarma Deresi memba kesiminden alınan SD2 nolu dere suyu örneğinin TDS içeriği $101.8 \mathrm{mg} / \mathrm{l}$, Sarma
Deresi mansap kesiminden alınan SD3 nolu dere suyunun TDS içeriği ise $234.3 \mathrm{mg} / 1 \mathrm{dir}$. Sarma Deresi memba kesiminden alınan SD5 nolu dere suyunun TDS içeriği $84.0 \mathrm{mg} / 1$ iken mansap lokasyonunun (SD6) TDS içeriği 252.4 mg/l'dır. Sarma Deresi mansap örnekleri (SD3 ve SD6) memba örneklerine (SD2 ve SD5) göre $\mathrm{Mg}, \mathrm{SO}_{4}$ ve $\mathrm{NO}_{3}$ iyonlarınca zengindir. Yağmur suyundaki $\mathrm{NH}_{4}$ ve $\mathrm{NO}_{3}$ gibi iyonların miktarı, memba kesimi dere suyu örneklerinde azalırken, mansap kesimi örneklerinde artış göstermektedir. Kurak dönemin SD5 ve SD6 nolu dere suyu örneklerinde $\mathrm{NH}_{4}$ iyonu ile, tüm yağış ve dere suyu örneklerinde $\mathrm{PO}_{4}$ iyonu deteksiyon limitinin altındadır

Çizelge 6. Yağış ve dere suyu örneklerinin ana iyon analiz sonuçları ve iyonların bolluk sıralanımı.

Table 6. Abundance order of ions and major ion analysis results of the Sarma stream water and rainfall samples.

\begin{tabular}{|c|c|c|c|c|c|c|c|c|c|c|c|c|}
\hline \multirow{2}{*}{$\begin{array}{l}\begin{array}{c}\text { Örnek } \\
\text { no }\end{array} \\
\text { İyon }\end{array}$} & \multicolumn{2}{|c|}{$\begin{array}{c}\text { SD1 } \\
\text { Yağmur suyu } \\
(2012\end{array}$} & \multicolumn{2}{|c|}{$\begin{array}{c}\text { SD2 } \\
\text { Dere suyu } \\
\text { (memba) } \\
(2012)\end{array}$} & \multicolumn{2}{|c|}{$\begin{array}{c}\text { SD3 } \\
\text { Dere suyu } \\
\text { (mansap) } \\
(2012)\end{array}$} & \multicolumn{2}{|c|}{$\begin{array}{c}\text { SD4 } \\
\text { Kar suyu } \\
(2013)\end{array}$} & \multicolumn{2}{|c|}{$\begin{array}{c}\text { SD5 } \\
\text { Dere suyu } \\
\text { (memba) } \\
(2013)\end{array}$} & \multicolumn{2}{|c|}{$\begin{array}{c}\text { SD6 } \\
\text { Dere suyu } \\
\text { (mansap) } \\
(2013)\end{array}$} \\
\hline & $\mathrm{mg} / \mathrm{l}$ & $\mathrm{mek} / \mathrm{l}$ & $\mathrm{mg} / \mathrm{l}$ & $\mathrm{mek} / \mathrm{l}$ & $\mathrm{mg} / \mathrm{l}$ & $\mathrm{mek} / \mathrm{l}$ & $\mathrm{mg} / \mathrm{l}$ & $\mathrm{mek} / \mathrm{l}$ & $\mathrm{mg} / \mathrm{l}$ & $\mathrm{mek} / \mathrm{l}$ & $\mathrm{mg} / \mathrm{l}$ & $\mathrm{mek} / \mathrm{l}$ \\
\hline $\mathbf{N H}_{4}^{+}$ & 0.2 & 0.0111 & 0.05 & 0.0027 & 0.05 & 0.0027 & 0.1 & 0.0055 & - & - & - & - \\
\hline $\mathrm{PO}_{4}^{4-}$ & - & - & - & - & - & - & - & - & - & - & - & - \\
\hline $\mathrm{Na}^{+}$ & 2.3 & 0.1000 & 3.7 & 0.1608 & 7.7 & 0.3347 & 1.8 & 0.0782 & 4.4 & 0.1913 & 5.4 & 0.2347 \\
\hline $\mathbf{K}^{+}$ & 1.2 & 0.0306 & 0.6 & 0.0153 & 1.8 & 0.0460 & 0.7 & 0.0170 & 0.1 & 0.0025 & 0.3 & 0.0076 \\
\hline $\mathrm{Ca}^{2+}$ & 3.4 & 0.1697 & 18.8 & 0.9385 & 49.2 & 2.4600 & 10 & 0.4992 & 15.3 & 0.7638 & 62.9 & 3.1402 \\
\hline $\mathrm{Mg}^{2+}$ & 0.4 & 0.0329 & 2.4 & 0.1980 & 4.94 & 0.4065 & 0.2 & 0.0164 & 2.2 & 0.1810 & 3.77 & 0.3102 \\
\hline $\mathrm{Cl}^{-}$ & 3.0 & 0.0846 & 2.87 & 0.0809 & 7.0 & 0.1974 & 1.33 & 0.0375 & 2.2 & 0.0620 & 4.6 & 0.1297 \\
\hline $\mathrm{NO}_{3}^{-}$ & 1.45 & 0.0233 & 1.11 & 0.0179 & 6.8 & 0.1096 & 0.49 & 0.0079 & 0.2 & 0.0032 & 6.17 & 0.0995 \\
\hline $\mathrm{SO}_{4}^{32-}$ & 5.29 & 0.1101 & 8.89 & 0.1851 & 15.1 & 0.3141 & 0.71 & 0.0147 & 6.0 & 0.1249 & 8.4 & 0.1749 \\
\hline $\mathrm{HCO}_{3}^{-}$ & 9.8 & 0.1606 & 63.4 & 1.0393 & 141.7 & 2.3229 & 30.5 & 0.5000 & 54 & 0.8852 & 161 & 2.6393 \\
\hline TDS & 27.0 & & 101.8 & & 234.3 & & 45.8 & & 84 & & 252.4 & \\
\hline $\begin{array}{l}\text { EC } \\
(\mu \mathrm{S} / \mathrm{cm})\end{array}$ & 46.9 & & 162.7 & & 371 & & 58.3 & & 106.5 & & 273 & \\
\hline $\begin{array}{l}\text { Katyonların } \\
\text { bolluk } \\
\text { sıralnımı }\end{array}$ & \multicolumn{2}{|c|}{$\begin{array}{c}\mathrm{Ca}>\mathrm{Na}+\mathrm{K}> \\
\mathrm{Mg}>\mathrm{NH}_{4}\end{array}$} & \multicolumn{2}{|c|}{$\begin{array}{c}\mathrm{Ca}>\mathrm{Na}+\mathrm{K}> \\
\mathrm{Mg}>\mathrm{NH}_{4}\end{array}$} & \multicolumn{2}{|c|}{$\begin{array}{c}\mathrm{Ca}>\mathrm{Na}+\mathrm{K}> \\
\mathrm{Mg}>\mathrm{NH}_{4}\end{array}$} & \multicolumn{2}{|c|}{$\begin{array}{c}\mathrm{Ca}>\mathrm{Na}+\mathrm{K}> \\
\mathrm{Mg}>\mathrm{NH}_{4}\end{array}$} & \multicolumn{2}{|c|}{$\begin{array}{c}\mathrm{Ca}>\mathrm{Na}+\mathrm{K}> \\
\mathrm{Mg}\end{array}$} & \multicolumn{2}{|c|}{$\begin{array}{c}\mathrm{Ca}>\mathrm{Mg}> \\
\mathrm{Na}+\mathrm{K}\end{array}$} \\
\hline $\begin{array}{l}\text { Anyonların } \\
\text { bolluk } \\
\text { siralnımı }\end{array}$ & \multicolumn{2}{|c|}{$\begin{array}{c}\mathrm{HCO}_{3}> \\
\mathrm{SO}_{4}>\mathrm{CI}>\mathrm{NO}_{3}\end{array}$} & \multicolumn{2}{|c|}{$\begin{array}{c}\mathrm{HCO}_{3}> \\
\mathrm{SO}_{4}>\mathrm{CI}>\mathrm{NO}_{3}\end{array}$} & \multicolumn{2}{|c|}{$\begin{array}{c}\mathrm{HCO}_{3}> \\
\mathrm{SO}_{4}>\mathrm{CI}>\mathrm{NO}_{3}\end{array}$} & \multicolumn{2}{|c|}{$\begin{array}{c}\mathrm{HCO}_{3}> \\
\mathrm{CI}>\mathrm{SO}_{4}>\mathrm{NO}_{3}\end{array}$} & \multicolumn{2}{|c|}{$\begin{array}{c}\mathrm{HCO}_{3}> \\
\mathrm{SO}_{4}>\mathrm{CI}>\mathrm{NO}_{3}\end{array}$} & \multicolumn{2}{|c|}{$\begin{array}{c}\mathrm{HCO}_{3}> \\
\mathrm{SO}_{4}>\mathrm{CI}>\mathrm{NO}_{3}\end{array}$} \\
\hline $\begin{array}{l}\text { İyonik } \\
\text { Denge } \\
\text { Hatası }\end{array}$ & \multicolumn{2}{|c|}{-7.8} & \multicolumn{2}{|c|}{-0.5} & \multicolumn{2}{|c|}{4.8} & \multicolumn{2}{|c|}{3.8} & \multicolumn{2}{|c|}{2.8} & \multicolumn{2}{|c|}{7.9} \\
\hline
\end{tabular}


Pehlivan

\section{Su - Kayaç Etkileşimi}

Yağmur, kar ve dere suyu örneklerine ait ana iyon analiz sonuçlarından Schoeller ve Piper diyagramları hazırlanmıştır (Şekil 3 ve 4). Schoeller diyagramına (Schoeller, 1962) göre, yağmur, kar ve dere sularındaki katyonların mek/1 siralanımları $\mathrm{Ca}>\mathrm{Na}+\mathrm{K}>\mathrm{Mg}$, anyonların siralanımlar1 ise kar suyu $(\mathrm{HCO} 3>\mathrm{CI}>\mathrm{SO} 4>\mathrm{NO} 3)$ hariç $\mathrm{HCO}_{3}>\mathrm{SO}_{4}>\mathrm{CI}>\mathrm{NO}_{3}$ şeklindedir. Yağmur suyu kar suyuna göre daha fazla $\mathrm{SO}_{4}, \mathrm{Cl}$ ve $\mathrm{NO}_{3}$ içermektedir (Çizelge 6).

(a)

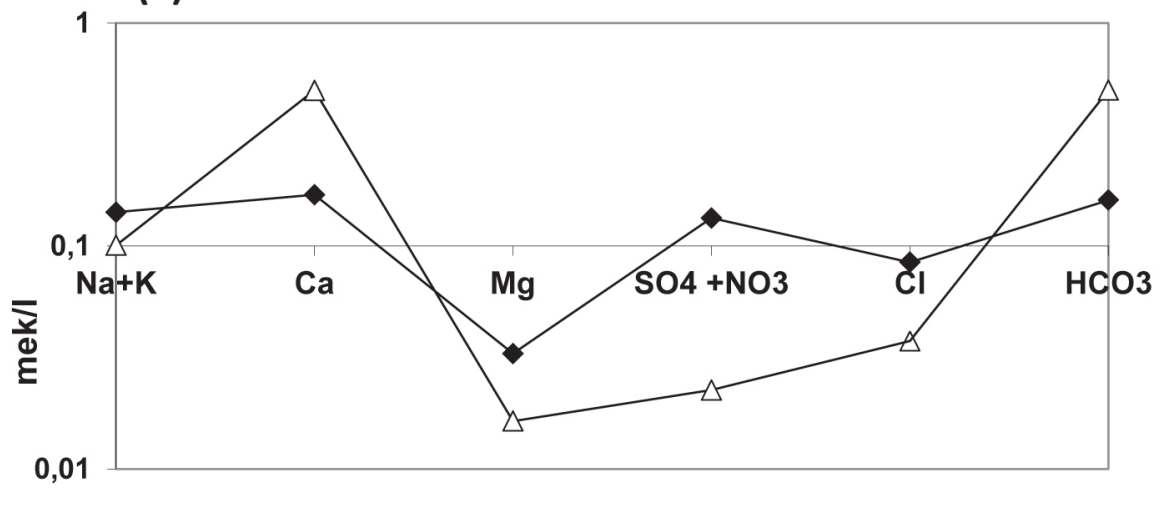

SD1 Yağmur suyu (2012) $\quad-$ SD4 Kar suyu (2013)

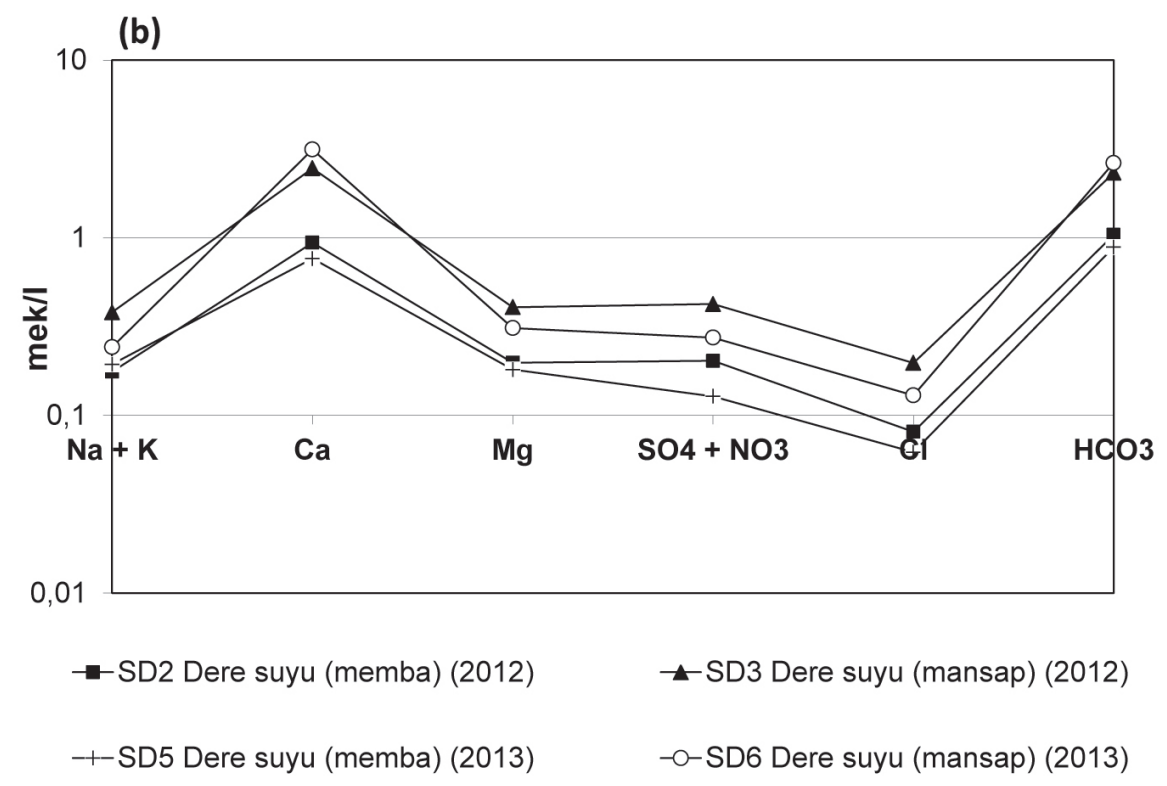

Şekil 3. (a) Yağmur ve kar suyu, (b) dere suyu örneklerinin Schoeller diyagramı.

Figure 3. The Schoeller diagram of (a) rainfall and snowmelt, and (b) the stream water samples. 


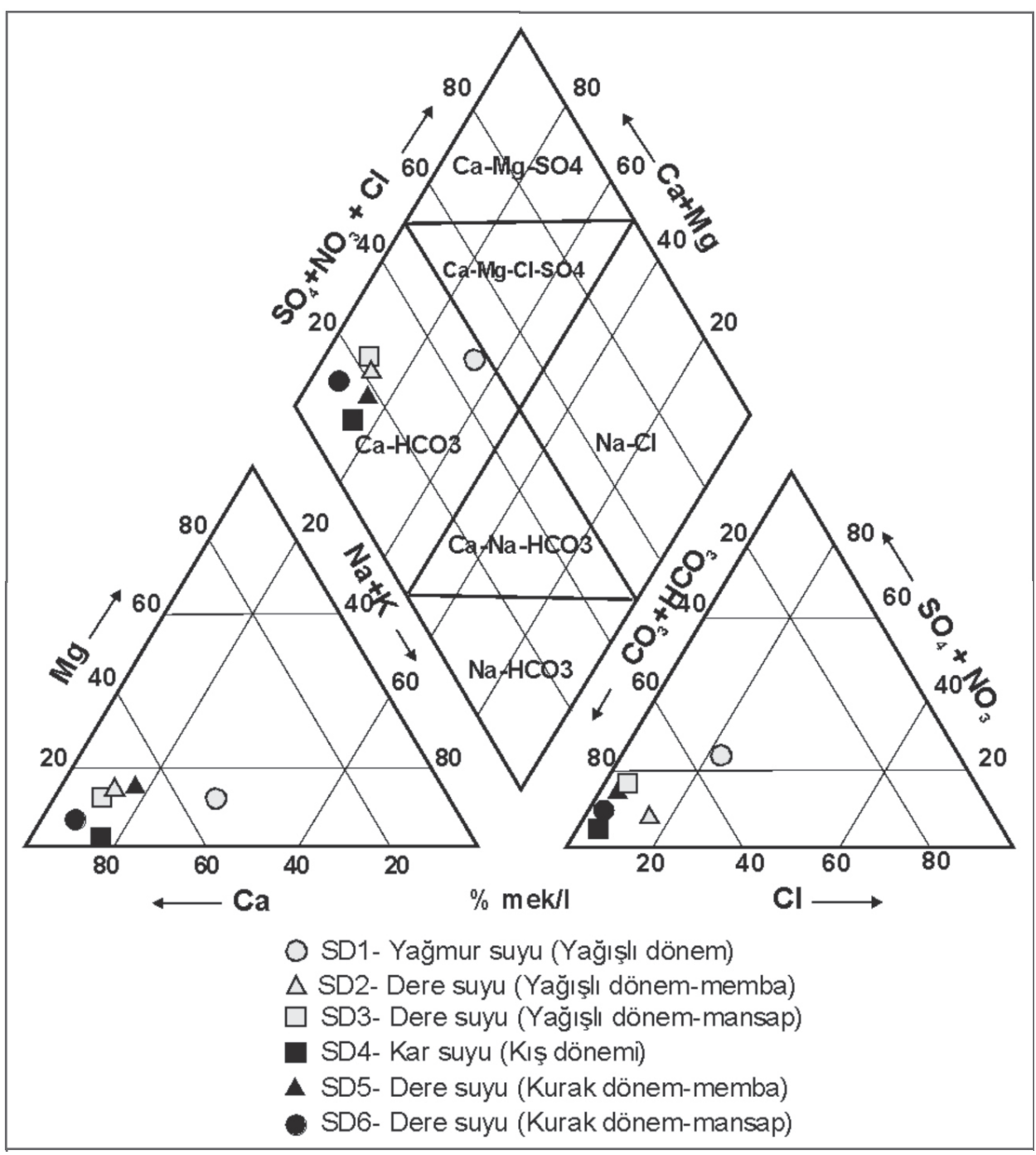

Şekil 4. Yağış ve dere suyu örneklerinin Piper diyagramı.

Figure 4. Piper diagram of the rainfall and the stream water samples.

Piper diyagramına (Piper, 1944) göre SD1 ve SD4 nolu yağ1ş örnekleri ile SD2, SD3, SD5 ve SD6 nolu dere suyu örneklerinin su tipi Ca$\mathrm{HCO}_{3}$ 'tür.

Yağış ve dere suyu örneklerinin TDS (toplam çözünmüş katı madde) (mg/l) ve $\mathrm{Na} /(\mathrm{Na}+\mathrm{Ca}) \quad(\mathrm{mg} / \mathrm{l})$ değerlerine göre Gibbs
(1970) diyagramındaki konumları Şekil 5'te verilmektedir. Gibbs diyagramına göre Sarma Deresi sularındaki ana iyon zenginleşmesi sukayaç etkileşimi ile gerçekleşmektedir. Ayrıca, k1ş ve yaz dönemi dere suyu örneklerinin $\mathrm{HCO}_{3} /$ $\mathrm{Na}$ ile $\mathrm{Ca} / \mathrm{Na}$ diyagramina (Gaillardet vd., 1999) göre (Şekil 6), dere sularına silikatler ve karbonatlardan iyon geçişi olmaktadır. 
Pehlivan

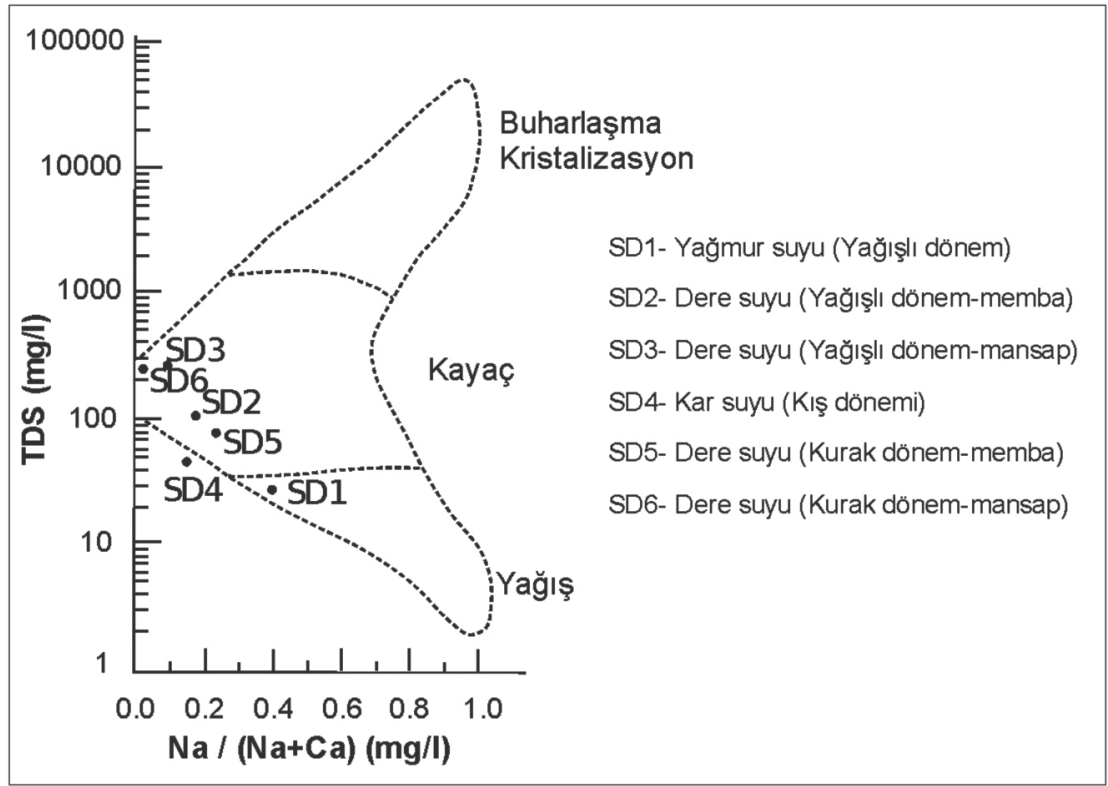

Şekil 5. Yağış ve dere suyu örneklerinin Gibbs diyagramı.

Figure 5. Gibbs diagram of the rainfall and the stream water samples.

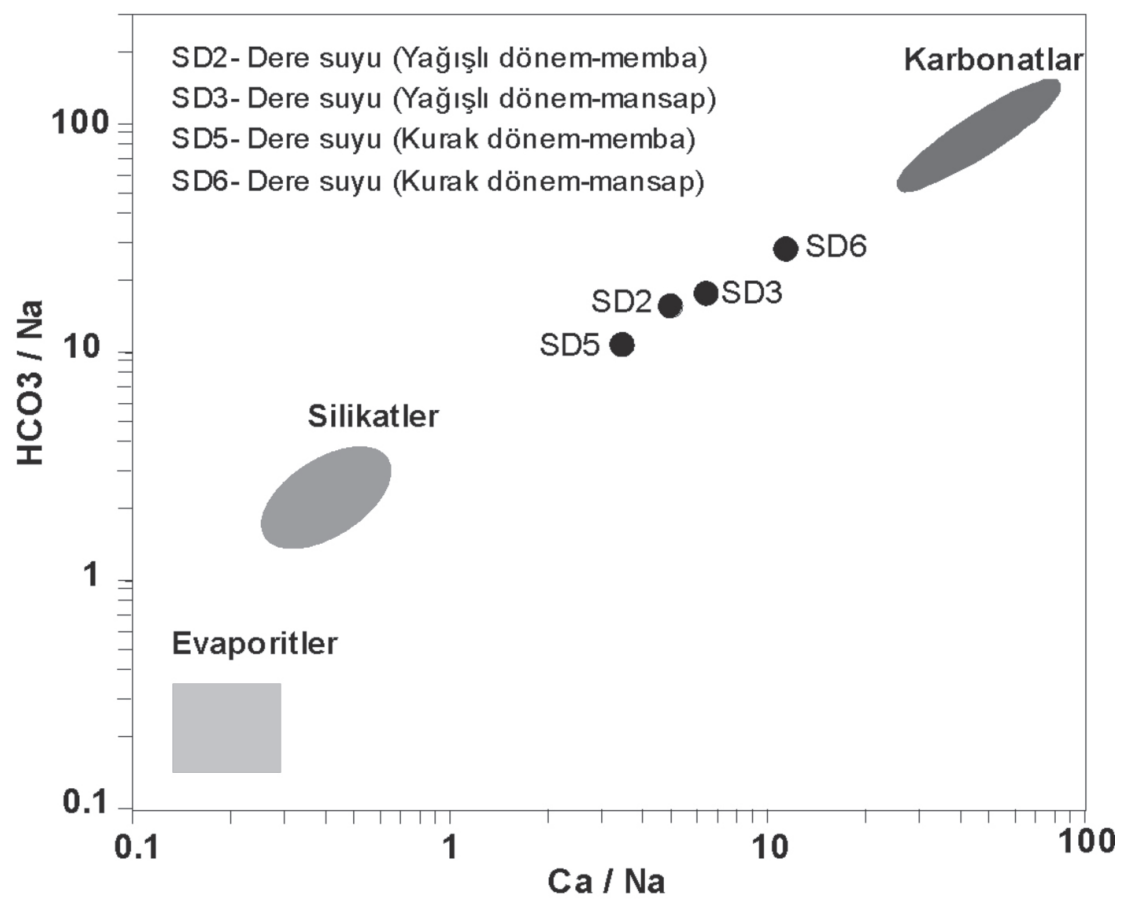

Şekil 6. Dere suyu örneklerinin $\mathrm{HCO}_{3} / \mathrm{Na}$ ve $\mathrm{Ca} / \mathrm{Na}$ diyagramındaki konumu.

Figure 6. Position of the stream water in $\mathrm{HCO}_{3} / \mathrm{Na}$ and $\mathrm{Ca} / \mathrm{Na}$ diagram. 


\section{YAĞIŞ VE SARMA DERESI SULARININ AĞIR METAL İÇERİĞİ}

Yağış (yağmur, kar) ve dere sularının yağışlı dönem (Aralık 2012), kış mevsimi (Şubat 2013) ve kurak dönem (Haziran 2013) örneklerindeki ağır metal ve bazı element içeriklerini belirlemek için yaptırılan $\mathrm{Al}, \mathrm{Fe}, \mathrm{As}, \mathrm{Ag}, \mathrm{Hg}, \mathrm{Co}, \mathrm{Cd}, \mathrm{Cr}$, $\mathrm{Pb}, \mathrm{Ni}, \mathrm{Ti}, \mathrm{Ba}, \mathrm{Mn}, \mathrm{Zn}, \mathrm{Cu}, \mathrm{Se}, \mathrm{Sb}, \mathrm{B}$ ve $\mathrm{U}$ elementlerine ait analiz sonuçları Çizelge 7'de verilmektedir. dere sularındaki Al, Ba, B, Fe, Mn ve Zn gibi elementler $10 \mathrm{ppb}$ ve üzeri konsantrasyona sahiptir. Yağış sularının toplam ağır metal içeriği, dere sularına göre oldukça düşüktür. Yeraltı suyu girdisine ek olarak Sarma Deresi'nin kaynağı olan yağışlar, su kayaç etkileşimi sonrasında bazı ağır metal ve elementlerce zenginleşmiştir. Sonbahar mevsiminin yağışlı dönemine ait yağmur suyu (SD1) ve dere suyu (SD2) örneklerine ait analiz sonuçları karşılaştırıldığında, $\mathrm{Al}, \mathrm{Sb}$,

Çizelge 7. Sarma Dere suyu ve yağış örneklerinin bazı element analiz sonuçları (ppb), standart sapma ve ortalama değerleri.

Table 7 Mean values, standard deviation and some element analysis results (ppb) of the Sarma Stream water and rainfall samples.

\begin{tabular}{ccccccccc}
\hline & $\begin{array}{c}\text { SD1 } \\
\text { Yağmur Suyu }\end{array}$ & $\begin{array}{c}\text { SD2 } \\
\text { Dere Suyu } \\
\text { (memba) }\end{array}$ & $\begin{array}{c}\text { SD3 } \\
\text { Dere Suyu } \\
\text { (mansap) }\end{array}$ & $\begin{array}{c}\text { SD4 } \\
\text { Kar suyu }\end{array}$ & $\begin{array}{c}\text { SD5 } \\
\text { Dere Suyu } \\
\text { (memba) }\end{array}$ & $\begin{array}{c}\text { SD6 } \\
\text { Dere Suyu } \\
\text { (mansap) }\end{array}$ & $\begin{array}{c}\text { Ortalama } \\
\text { (Dere sular1 } \\
\text { için) }\end{array}$ & $\begin{array}{c}\text { Standart } \\
\text { Sapma } \\
\text { (Dere suları } \\
\text { için) }\end{array}$ \\
\hline $\mathbf{A l}$ & 56.9 & 27.8 & 85.5 & 254 & 105 & 227 & 111.3 & 72.6 \\
$\mathbf{S b}$ & 0.1 & $<0.1$ & $<0.1$ & 0.1 & $<0.1$ & $<0.1$ & $<0.1$ & 0 \\
$\mathbf{A s}$ & 0.3 & 0.8 & 0.4 & 0.2 & 0.79 & 0.56 & 0.64 & 0.16 \\
$\mathbf{B a}$ & 7.1 & 21.6 & 84.5 & 45.5 & 19.6 & 68 & 48.4 & 32.8 \\
$\mathbf{B}$ & $<10$ & 11 & 21 & $<10$ & 11 & 18 & 15.3 & 5.05 \\
$\mathbf{C d}$ & $<0.05$ & $<0.05$ & $<0.05$ & $<0.05$ & $<0.05$ & $<0.05$ & $<0.05$ & 0 \\
$\mathbf{C r}$ & 1.66 & 0.9 & 1 & 1.59 & 0.77 & 1.16 & 0.96 & 0.16 \\
$\mathbf{C o}$ & $<0.1$ & $<0.1$ & 0.1 & $<0.1$ & 0.12 & 0.26 & 0.16 & 0.08 \\
$\mathbf{C u}$ & 2.38 & 1.39 & 1.93 & 8.3 & 2.72 & 1.55 & 1.89 & 0.59 \\
$\mathbf{F e}$ & 87 & 45 & 117 & 88 & 147 & 301 & 152.5 & 107.9 \\
$\mathbf{P b}$ & 1 & 0.4 & 0.3 & 1.5 & 0.77 & 0.97 & 0.61 & 0.31 \\
$\mathbf{M n}$ & 4.86 & 3.95 & 55.8 & 9.59 & 11.8 & 26.2 & 24.4 & 22.8 \\
$\mathbf{H g}$ & $<0.05$ & $<0.05$ & $<0.05$ & $<0.05$ & $<0.05$ & $<0.05$ & $<0.05$ & 0 \\
$\mathbf{N i}$ & 0.9 & $<0.5$ & 0.8 & 1.4 & 1.34 & 1.35 & 1.16 & 0.46 \\
$\mathbf{S e}$ & $<1$ & $<1$ & $<1$ & $<1$ & $<1$ & $<1$ & $<1$ & 0 \\
$\mathbf{S i}$ & 254 & 5650 & 3710 & 465 & 6060 & 4700 & 5030 & 1048.3 \\
$\mathbf{A g}$ & 0.024 & 0.010 & 0.010 & 0.013 & 0.23 & 0.064 & 0.08 & 0.1 \\
$\mathbf{T i}$ & $<10$ & $<10$ & $<10$ & $<10$ & $<10$ & $<10$ & $<10$ & 0 \\
$\mathbf{U}$ & $<0.010$ & $<0.028$ & 0.25 & 0.15 & $<0.03$ & 0.2 & 0.13 & 0.11 \\
$\mathbf{V}$ & $<1$ & $<1$ & $<1$ & $<1$ & $<1$ & 1.1 & 1.03 & 0.1 \\
$\mathbf{Z n}$ & 15.7 & $<3$ & 3.1 & 45 & 6.2 & 4.3 & 3.9 & 1.8 \\
\hline
\end{tabular}

Analiz sonuçlarına göre, kar suyu yağmur suyuna göre $\mathrm{Al}, \mathrm{Ba}, \mathrm{Cu}, \mathrm{Pb}, \mathrm{Mn}, \mathrm{Ni}, \mathrm{Si}, \mathrm{U}$ ve $\mathrm{Zn}$ gibi elementlerce zengindir. Yağış ve
$\mathrm{Ag}, \mathrm{Cr}, \mathrm{Fe}, \mathrm{Pb}$ ve $\mathrm{Zn}$ gibi elementlerin yağmur suyunda daha fazla miktarda bulunuyor olmas1 düşündürücüdür. Sarma Deresi’nin Karadeniz’e 
dökülmeden önceki lokasyonundan alınan SD3 nolu dere suyu örneği ise, SD2 nolu dere suyu örneğine göre $\mathrm{Al}, \mathrm{Ba}, \mathrm{B}, \mathrm{Mn}, \mathrm{U}$ ve $\mathrm{Fe}$ elementlerince daha zengindir.

\section{SARIYAYLA BARAJ SUYUNUN İÇILEBİLIRLIĞİ VE SU KALİTESİ}

İnşaa halindeki Sarıyayla Baraj1 tamamlandığında, barajda birikecek olan ham su, Akçakoca İlçesinde içme ve kullanma suyu olarak tüketilecektir. Bu nedenle, Sarma Deresi suyunun içilebilirliğini değerlendirebilmek için Dünya Sağl1k Örgütü (WHO, 2011), ABD Çevre Koruma Ajansı (EPA, 2009), İnsanı Tüketim Amaçlı Sular hakkında Yönetmelik (RG 25730, 2005) ve Avrupa Birliği (EU, 1998)'nin içme suyu gösterge limit değerlerini dikkate almak gerekir. Değerlendirme sonucunda, kar suyunda Al iyonu bakımından gösterge limit değerin (0.2 mg/l) aşıldığ görülmektedir. Söz konusu Al elementi içeriği, kurak döneme ait (SD6 nolu mansap lokasyonu) dere suyu örneğinde de belirlenmiştir. Bu veri, Sarıyayla Barajı'nda su tutulmaya başlandığında, baraj suyunun Al elementince zenginleşebileceğinede işarettir. Aynı zamanda, SD6 nolu dere suyu örneğinde Fe elementi bakımından da $0.3 \mathrm{mg} / 1$ olan gösterge limit değer aşılmaktadır. Yağışlı döneme ait (SD3 nolu mansap lokasyonu) dere su örneğinde ise Mn iyonunca da gösterge limit değer aşılmaktadır.

Sarma Deresi'nin su kalitesini tespit etmek için ise yağmur, kar ve dere sularının element ve iyon içerikleri, Yerüstü Su Kalitesi Yönetmeliği (YSKY, 2015) limit değerleri ile karşılaştırılmıştır. Böylelikle, Sarma Deresi'nden kurak dönemde alınan (SD6 nolu mansap lokasyonuna ait) dere suyunun su kalite sınıfi, $\mathrm{NH}_{4}, \mathrm{NO}_{3}$ ve Fe iyonları bakımından 2 (az kirlenmiş su) olarak belirlenmiştir.

\section{SONUÇLAR}

Sarma Deresi havzasına düşen yağışlar ile Sarma Deresi sularının su tipi $\mathrm{Ca}-\mathrm{HCO}_{3}$ 'tür. Yağmur, kar ve dere sularındaki katyonların (mek/l miktarlarına göre) sıralanımları benzerdir. Aynı benzerlik, anyonlarının siralanımında görülmemektedir. Çünkü, kar suyu $\mathrm{Cl}$ iyonunca daha zengindir.

Sarma Deresi havzasında görülen asit yağışların, Sarma Deresi suyunun Fe, Al ve Mn gibi elementlerce daha da zenginleşmesine etkisi vardır. Kumtaşının (SD12WR) ayrışma ürünü toprak (SD7S) örneği ile arduvazın (SD6WR) ayrışma ürünü toprak (SD9S) örneğindeki ana ve iz element içeriklerinin kayaç örneklerine göre düşük olmasında su-kayaç etkileşimi etken olmuştur. Su havzasında gerçekleşen yağışın asidik karakterli olması toprak örneklerindeki elementlerin yüzey ve yeraltı suyuna geçişini kolaylaştırmıştır.

Sarma Deresi çamuru örnekleri kuvars, plajiyoklas ve kil minerallerinden oluşur. Dere çamuru ve askıda katı madde örneklerindeki ortak kil minerali, illit ve montmorillonittir. $\mathrm{Bu}$ minerallere, memba lokasyonu çamur örneğinde (SD11CM) klorit, mansap lokasyonu çamur örneğinde (SD21CM) ise kaolinit minerali eklenmektedir. SD11CM nolu dere çamuru ve SD11AK nolu askıda katı madde örneklerinin kimyasal ayrışma indeks (CIA) değerleri, Sarma Deresi havzasinda orta derecede kimyasal ayrışmanın hüküm sürdüğünü göstermektedir. Askıda katı madde örneğinin (SD11AK), Sarma Deresi çamur örneğine (SD11CM) göre $\mathrm{Al}_{2} \mathrm{O}_{3}$, 
$\mathrm{TiO}_{2}$ ve $\mathrm{Zn}$ elementlerince daha zengin olmasında kil minerallerinin adsorbe özelliği etkindir.

Yağmur, kar ve dere suyu örneklerinde bulunan $\mathrm{Al}, \mathrm{Ba}, \mathrm{B}, \mathrm{Fe}, \mathrm{Mn}$ ve $\mathrm{Zn}$ gibi elementler $10 \mathrm{ppb}$ ve üzeri konsantrasyona sahiptir. Bölgedeki topoğrafik yükseltinin ve yüksek eğimin, su kayaç etkileşiminin uzun süreli olmasını engellediği için, su kalitesine olumlu yönde etkisi söz konusudur.

Sarma Deresi ham suyunun insan sağlığına olası etkisi, Dünya Sağlık Örgütü, ABD Çevre Koruma Ajansı, İnsanı Tüketim Amaçlı Sular ve Avrupa Birliği içme suyu gösterge limit değerlerine göre değerlendirildiğinde, kar suyunda Al elementi bakımından gösterge limit değerin aşıldığı, Zn elementi bakımından ise limit değere çok yaklaşıldığ 1 görülmektedir. Bu zengin $\mathrm{Al}$ elementi içeriği, kurak döneme ait dere suyu örneğinin su kimyasına da yansımaktadır. $\mathrm{Bu}$ durum, Sariyayla Barajı'nda su tutulmaya başlandığında baraj suyunun Al elementince de zengin olacağını göstermektedir. $\mathrm{Bu}$ nedenle, Sarıyayla Barajı ham suyunda iyileştirme ve arıtma işlemlerine gereksinim olabilir. Öte yandan, Sarma Deresi'nin mansap lokasyonu için yağışılı döneme ait dere suyunda (SD3) Mn elementince, kurak döneme ait dere suyunda (SD6) ise $\mathrm{Fe}$ elementince de gösterge limit değerler aşılmaktadır. Yağmur suyunun (SD1) $\mathrm{NH}_{4}$ iyonu ve dere suyunun (SD6) ise $\mathrm{NO}_{3}$ iyonu bakımından su kalitesi 2 olarak belirlenmiştir. $\mathrm{Bu}$ veriler, $\mathrm{Al}, \mathrm{Zn}$ ve $\mathrm{Fe}$ iyonlarının dere sularında zenginleşmesinde su kayaç etkileşiminin etken olduğunu, $\mathrm{NO}_{3}$ iyonu zenginleşmesine ise yağmur suyu ve tarımsal üretimin etken olduğunu düşündürmektedir.

Sarma Deresi havzasında $\mathrm{m}^{2}$ ye bol yağış bırakan ve kısa süreli olan (20-40 dk süren) asidik yağışların gerçekleştiği dönemlerde, Sarma Deresi suyu, $\mathrm{Fe}, \mathrm{Al}, \mathrm{Zn}$ ve $\mathrm{Mn}$ gibi ağır metal ve bazı elementlerce zenginleşmektedir (Pehlivan ve Emre, 2016). Söz konusu ağır metallerin veya benzerlerinin insan sağlı̆̆ına olası olumsuz etkilerinin önlen(ebil)mesi için, Türkiye'nin kuzeyinde, batıdan - doğuya doğru Kırklareli ile Artvin arasındaki bölgede, Devlet Su İşleri (DSI) ve/veya Belediyeler tarafından halkın içme suyu ihtiyacı için kullanılan Sakarya, Zonguldak, Kastamonu, Sinop, Samsun, Ordu, Ünye, Trabzon, Rize ve Artvin illerindeki göl, gölet ve içme suyu barajlarına ait su havzalarına sağanak türde düşen yağışlara dikkat edilmelidir. Söz konusu havzalardaki baraj veya göletlerde bu tür yağışlar ile biriken su, tüketim amacıyla yerleşim birimlerine verilmeden önce, ham suların fiziksel iyileştirmeden ziyade, arıtılmasını gerektirebilir.

\section{KATKI BELIRTME}

$\mathrm{Bu}$ araştırma, İstanbul Üniversitesi Araştırma Fonu tarafından desteklenmiştir. Proje No : 24781. Yazar, makaleyi inceleyen ve bilimsel gelişimine katkı koyan hakemlere içtenlikle teşekkür eder.

\section{KAYNAKLAR}

Alp, K., Yazgan, M. S., Citil, E., Toros, H., Reis, B., 2004. Atmospheric deposition and its effects on drinking water resources of Istanbul. International symposium on water resources and environmental impact assessment, DSI, 223232, Istanbul.

Basak, B., Alagha, O., 2010. Trace metals solubility in rainwater: evaluation of rainwater quality at a watershed area, Istanbul. Environmental Monitoring and Assessment, 167, 493-503. 
Charlson, R. J., Rodhe, H., 1982. Factors Controlling the Acidity of Natural Rainwater. Nature, 95, 683-685.

Carlson, C. L., Haines, B. L., 1989.Acidic Precipitation. "Biological and Ecological Effects". SpringerVerlag New York Incorporation, 2, 1-50.

Chesworth, W., Dejou, J., Larroque, P., 1981. The weathering of basalts and relative mobilities of the majör elements at Belbex. France Geochimica et Cosmochimica Acta, 45, 1235-1243.

EPA (United States Environmental Protection Agency), 2009. National Primary Drinking Water Ragulations. Office of Water, EPA 816-F-09004, 6p., USA (http://www.epa.gov/safewater/ contaminants/index.html).

European Union, 1998. Council Directive 98/83/ EC of 3 Nowember 1998 on the quality of water intended for human consumption. Offical Journal, 330, 32-54.

Gaillardet, J., Dupre, B., Allegre, C. J., 1999. Geochemistry of large river suspended sediments: Silicate weathering or recycling tracer? Geochimica et Cosmochimica Acta, 63 (23/24), 4037-4051.

Gibbs, R. J., 1970. Mechanisms controlling world water chemistry. Science, 170, 1088- 1090.

Gorham, E., 1976. Acid precipitation and its influence. Upon aquatic ecosystems-an overview. Water, air, and soil pollution, 6, 457-481.

Hettelingh, J. P, Hordijk, L., 1986. Environmental conflicts: The case of Acid Rain in Europe. The Annals of Regional Science, 20 (3), 38-52.

Im, U., Christodoulaki, S., Violaki, K., Zarmpas, P., Kocak, M., Daskalakis, N., Mihalopoulos,N., Kanakidou, M., 2013. Atmospheric deposition of nitrogen and sulfur over southern Europe with focus on the Mediterranean and the Black Sea. Atmospheric Environment, 81, 660-670.

İlhan, A. I, Öz, N., Dündar, C., Kenet, F., Balta, T., 2006. Asit Yağmurları ve Hava Kirliliği Değerlendirme Raporu. Devlet Meteoroloji İşleri Genel Müdürlüğü, Teknik Rapor, http://www.mgm.gov.tr/FILES/arastirma/ AsitYagmurlariDegerlendirmeRaporu.pdf, 361 s.
Keskin, T. E., 2010. Nitrate and heavy metal pollution resulting from agricultural activity: a case study from Eskipazar (Karabuk, Turkey). Environmental Earth Sciences, 61, 703-721.

Kumar, A., Kaur, I., Mathur, R. P., 1998. Water Quality and Metal Enrichment in Bed Sediments of the Rivers Kali and Hindon India. Environmental Geochemistry and Health, 20, 53-60.

Lajtha, K., Jones, J., 2013. Trends in cation, nitrogen, sulfate and hydrogen ion concentrations in precipitation in the United States and Europe from 1978 to 2010: a new look at an old problem. Biogeochemistry, 116, 303-334.

Lee, S. Y., Kim, S. J., Baik, M. H., 2009. Chemical weathering of granite under acid rainfall environment, Korea. Environmental Geology, $55,853-862$.

Menz, F. C., Seip, H. M., 2004. Acid rain in Europe and the United States: an update. Environmental Science and Policy, 7, 253-265.

MGM (Meteoroloji Genel Müdürlüğü), 2013. 1970 - 2013 yılları yağış değerleri, Türkiye Yağışları, http://www.mgm.gov.tr/veridegerlendirme/ yillik-toplam-yagis-verileri.aspx\#sfU, $41 \mathrm{~s}$.

MGM (Meteoroloji Genel Müdürlüğü), 2014. 2004 2014 yılları yağış ve sıcaklık değerleri, Akçakoca Meteoroloji İstasyonu, http://www.mgm.gov.tr/ tahmin/il-ve-ilceler.aspx?m=AKCAKOCA, 1 s.,

Nesbitt, H. W., 1979. Mobility and fraction of rare earth elements during weathering of a granodiorite. Science, 279, 206-210.

Nesbitt, H. W., Young, G. M., 1982. Early proterozoic climates and plate motions inferred from major element chemistry of lutites. Nature, 299, 715717.

Pehlivan, S., Bilginer, E., Aksay, A., 2002. 1/100000 Ölçekli Türkiye Jeoloji Haritaları No: 33, Adapazarı G26 Paftası, MTA Jeoloji Etütleri Dairesi, $28 \mathrm{~s}$.

Pehlivan, R., Emre, H., 2016. Potability and hydrogeochemisty of the sarma stream water, düzce, Turkey. Water Resources (In Press, Accepted Manuscript), 17. 
Piper, A. M., 1944. A Graphic Procedure in the Geochemical Interpretation of Water Analyses. American Geophysical Union, 25, 914-923.

Piper, D. Z., Ludington, S., Duval, J. S., Taylor, H. E., 2006. Geochemistry of Bed and Suspended Sediment in the Mississippi River System, Provenance Versus Weathering and winnowing. Science of the Total Environment, 362, 179-204.

Price, J. R., Velbel, M. A., 2003. Chemical weathering indices applied to weathering profiles developed on heterogeneous felsic metamorphic parent rocks. Chemical Geology, 202, 397-416.

RG 25730, 2005. İnsani Tüketim Amaçlı Sular Hakkında Yönetmelik, Sağlık Bakanlığı, Resmi Gazete, 27 s.

Schoeller. H., 1962. Les eaux souterraines, Hydrologie dynamique et chimique, Recherche, Exploitation et Évaluation des Ressources. Masson et cie, Paris, Vol 1, $642 \mathrm{p}$.

Stallard, R. F., 1988. Weathering and erosion in the humid tropics, in: Lerman a, meybeck m, eds, physical and chemical weathering in geochemical cycles, Kluwer Academic Publishers, Dordrecht, 225-246.

Sun, L., Wang, Y., Yue, T., Yang, X., Xue, L., Wang, W., 2015. Evaluation of the behavior of clouds in a region of severe acid rain pollution in southern China: species, complexes, and variations.
Environmental Science and Pollution Research, $22,14280-14290$.

Taylor, S. R., McLennan, S. M., 1995. The Geochemical Evolution of the Continental Crust. Reviews in Geophysics, 33, 241-265.

Toros, H., Şen, O., Saylan, L., 1997. İstanbul'da asit yağışları ve çevreye etkileri. Meteorolojik Karakterli Doğal Afetler Sempozyumu, TMMOB, 79-89.

Toros, 2000. İstanbul'da asit yağışları, kaynakları ve etkileri. İstanbul Teknik Üniversitesi Fen Bilimleri Enstitüsü, İstanbul, Doktora Tezi, $97 \mathrm{~s}$ (yayımlanmamış).

Tuncel, G., Balkas, T., Arami, M., Ataman, Y., Ölmez, I., Tuncel, S., Hacisalihoğlu, G., Eliyakut, F., Anwari, M., Herman, D. 1991. Karadeniz Atmosferinde Eser Element Taşınımı, TUBITAK, DEBCAG $48:$ 1-153.

WHO, 2011. Guidelines for Drinking-Water Quality. Fourth Edition, World Health Organization, Geneva, Switzerland, 541 p.

YSKY, 2015. Yüzeysel su kalitesi yönetimi yönetmeliğinde değişiklik yapılmasına dair yönetmelik, Resmî Gazete, Say1 : 29327, 9 s.

Zhou, Y., Wang, Y., Li, Y., Zwahlen, F., Boillat, J., 2013. Hydrogeochemical characteristics of central Jianghan Plain, China. Environmental Earth Sciences, 68, 765 -778. 